\title{
Notações da Matemática Infantil: Igualar e Repartir Grandezas na Origem das Estruturas Multiplicativas
}

\author{
Maria Lucia Faria Moro ${ }^{12}$ \\ Universidade Federal do Paraná
}

\begin{abstract}
Resumo
O estudo trata da aprendizagem das estruturas aditivas em sua passagem às multiplicativas conforme o modelo da equilibração e as proposições de Vergnaud sobre campos conceituais. Descreve a natureza e as transformações de notações infantis em tarefas de igualização e de repartição de grandezas, e verifica a significação das notações produzidas no exame das relações psicogenéticas entre aquelas estruturas. Os 12 participantes (6,4 a 9,5 anos de idade), alunos de duas escolas públicas de periferia urbana de duas regiões metropolitanas diferentes, executaram, em tríades, tarefas com momentos alternados de execução prática e de notação interpretada do executado. A análise qualitativa microgenética dos dados videografados resultou em tipos de notação e em tendências de transformação conceitual reveladas pelas notações. A discussão sublinha a natureza e as alterações das notações descritas, e o lugar relevante, nas relações psicogenéticas entre as estruturas consideradas, de esquemas inerentes a ambas, igualização e repartição.

Palavras-chave: Notações matemáticas; iniciação aritmética; estruturas aditivas e multiplicativas.
\end{abstract}

Notations from Children's Mathematical Thinking:

Equalizing and Dividing Quantities at the Roots of Multiplicative Structures

\begin{abstract}
The paper concerns the learning of additive structures on its way to the multiplicative ones according to the equilibration model and Vergnaud's propositions about conceptual fields. It describes the nature and the changes of children's notations produced on tasks of equalization and partition of quantities, and verifies the meaning of those notations in the study of the psychogenetic relationship between those structures. The 12 participants (6,4 to 9,5 years old), attending two State Elementary Schools from suburbs of two different metropolitan areas, performed in triads the tasks, which alternated moments of practical compositions, notations production and their interpretation. The qualitative microgenetic analysis of videotaped data resulted in notation types and in tendencies of the conceptual transformations shown by the notations. The discussion underlines the nature and the progression of the described notations, and the relevant role of equalization and repartition as inherent schemata to the psychogenetic relationship between the focused structures.

Keywords: Mathematical notations; arithmetical initiation; additive and multiplicative structures.
\end{abstract}

$\mathrm{Na}$ literatura contemporânea de psicologia da educação matemática, é marcante a presença de resultados que apontam para o expressivo lugar que os sistemas de notação matemática ocupam na compreensão de conceitos e relações da matemática na escola, como também para a complexa elaboração desses sistemas como objeto de conhecimento em si próprios.

O estudo ora relatado foi realizado com os seguintes objetivos: o de descrever a natureza e as transformações de notações infantis relativas a tarefas centradas na igualização de parcelas e na repartição de grandezas, destinadas à elaboração de relações aditivas e multiplicativas; o de verificar a significação das notações produzidas no exame das relações psicogenéticas entre as estruturas aditivas e as multiplicativas. Ele é parte de um projeto maior que investiga, segundo a

\footnotetext{
${ }^{1}$. Trabalho realizado mediante apoio da CAPES (bolsa de professor visitante na UNICAMP) e do CNPq (bolsa de professor pesquisador na UFPR). Agradecemos a essas instituições, bem como à direção, corpo docente e alunos das escolas que serviram como campo.

${ }^{2}$ Endereço para correspondência: Rua Ubaldino do Amaral, 760, 901, 80060190 , Curitiba, PR. Fone (41)262-5173/ Fax (41)3605117.E-mail:mlfmoro@sul.com.br
}

ótica construtivista de Piaget, a aprendizagem das estruturas aditivas e sua passagem às multiplicativas com alunos de $1^{\mathrm{a}}$ e de $2^{a}$ séries do ensino fundamental, agrupados em tríades.

A publicação em 1941 das pesquisas de Genebra sobre a gênese do número nas crianças (Piaget \& Szeminska, 1971) constituiu-se em um "divisor de águas" para a concepção das quatro operações aritméticas clássicas como objeto de conhecimento em construção desde idades precoces.

A identificação e descrição de níveis progressivos da complexa organização de esquemas específicos às composições e decomposições aditivas e multiplicativas, como também resultados posteriores sobre o que se chamou de aritmetização do número (Gréco, Grize, Papert \& Piaget, 1960; Gréco \& Morf, 1962), provocaram expressivas investigações, na mesma e em outras linhas teóricas, sobre o aparecimento e/ou a aquisição das quantificações numéricas e de outras manifestações aritméticas das crianças (Ex.: Bideaud, Meljac \& Fischer, 1991). Em conseqüência, indicações sobre as necessárias mudanças no trato das quatro operações como conteúdo de ensino escolar fizeram-se ouvir dos mais diversos lados. 
Uma das formulações mais interessantes e produtivas a esse respeito veio da teoria dos campos conceituais de Gérard Vergnaud (Ex.: Vergnaud, 1981, 1990, 1994).

Essa perspectiva permite ver as operações de adição e de subtração como parte do campo conceitual das estruturas aditivas, e as de multiplicação e divisão como parte do campo das estruturas multiplicativas. Configuram-se essas operações como sistemas de esquemas de várias ordens, aplicáveis a diversas situações, e que se coordenam progressivamente em uma construção complexa, em níveis psicogenéticos diferentes, não limitados aos da aritmética. Logo, têm um processo de compreensão que vai além do período da escolaridade fundamental.

Construir um conceito também quer dizer elaborar um conjunto de representações simbólicas interrelacionadas. Porém, Vergnaud $(1981,1989-1990,1990)$ alerta para a importante diferença entre o conceito e sua representação, entre os significados conceituais e os sistemas de significantes que os expressam. Não fazer esta diferença traria, em matemática, a idéia errônea de que os símbolos e as operações sobre eles são a essência do conhecimento matemático.

Vergnaud (1994) vale-se das idéias de esquema (organização invariante da conduta para determinada classe de situações, na acepção utilizada pela epistemologia genética) e de situação, para sustentar a possibilidade de comunicação na aprendizagem da matemática na escola. Neste contexto (como em outros), há dificuldades de comunicação pela ausência de correspondência plena entre significantes e significados ou pelas ambigüidades da língua, mas principalmente por causa de os alunos disporem de esquemas conceituais diversificados (invariantes operatórios diferentes). E estes os levam a interpretar de várias maneiras os símbolos matemáticos, as formas lingüísticas empregadas no ensino, as quais trazem, por si sós, muitas armadilhas.

O conceito de esquema permite a Vergnaud (1996) entender as relações e as defasagens entre saberes em atos e saberes teóricos, quando esses saberes permitem a ação em domínios onde a teoria é pobre ou inexistente, defendendo que a ação pode alimentar-se da teoria e viceversa. Assim, os esquemas (de diferentes níveis de organização cognitiva) aperfeiçoam-se na teorização (representação), mesmo parcial, incompleta, própria do sujeito, dos elementos que os compõem.

Se a noção de esquema é importante para interpretar-se a conceitualização do real a partir da ação, também o são os resultados de Piaget $(1974,1978)$ sobre o papel da tomada de consciência da ação na construção cognitiva. Tornando a ação objeto de reflexão pelo sujeito, esse processo envolve necessariamente formas diversas de representação da ação e de suas relações. Por exemplo, quando explicitada pela palavra, a ação se transforma. Nessa perspectiva, esta explicitação (via diferentes linguagens) não tem apenas a função de comunicar objetos e suas relações. Ela transforma os conceitos, trazendo novos esquemas. Logo, é necessário analisar o papel da linguagem, dos sistemas simbólicos, na identificação e na delimitação de domínios pertinentes: “....sem a linguagem natural e sem o simbolismo, a teoria seria impossível..." (Vergnaud, 1996, p. 289).

Portanto, afora permitir tratar de modo mais consistente as quatro operações da aritmética clássica como estruturas conceituais, e de dar espaço para estudar suas inter-relações psicogenéticas, a teoria dos campos conceituais interessa sobremaneira ao ensino escolar porque permite melhor analisar a relação dialética ali ocorrente entre ação, situação prática e verbalização teórica (Vergnaud, 1990). Fornece, assim, elementos pertinentes para se trabalhar a construção de conceitos segundo a perspectiva da importância da ativação do processo da tomada de consciência da ação dos sujeitos para haver seu processo de conceitualização, como também para ser estudada sua explicitação notacional como parte transformadora desse processo de construção.

Essas são algumas das razões para que, neste trabalho, olhássemos as notações das crianças, e como por elas interpretadas, como dimensão transformadora do processo de construção conceitual focalizado, mediante tarefas de aprendizagem em que momentos de execução prática (com material), referentes aos aspectos conceituais em foco, fossem alternados, não só com os de interpretação verbal do executado, mas, sobretudo, com os de produção de notações das realizações práticas e de interpretação dessas notações. Nesse gênero de situação, as hipóteses próprias das crianças são referência principal à ativação, pelo adulto, da ação dos fatores da construção dos esquemas conceituais do aprendiz.

$\mathrm{O}$ interesse de estudiosos pela natureza dos sistemas notacionais da matemática tem-se traduzido, em décadas recentes, por vários de tipos de investigação.

Estudos sobre a psicogênese do sistema da escrita numérica arábica convencional retratam, desde idades precoces, a complexa atividade das crianças (principalmente as de sociedades urbanas) de dar significado às marcas de quantificação que encontram, e às que produzem (A. Sinclair, 1990; H. Sinclair, 1990; H. Sinclair \& A. Sinclair, 1986). Logo, essa perspectiva também defende a presença das dimensões seguintes, entre si articuladas - produção de marcas relativas a quantidades e interpretação dessas marcas pela criança para que ocorra a construção daquele sistema.

Na produção simbólica há diversas formas de representar coleções, mas na interpretação dos numerais é importante atender tanto à forma como ao significado pois, nos sistemas de representação, o significado só pode ser expresso pela forma, devendo a criança trabalhar, então, com os dois aspectos ao mesmo tempo para chegar à utilização 
significativa do sistema da escrita numérica (H. Sinclair, 1988, 1990; H. Sinclair \& A. Sinclair, 1986). É assim que, no processo de elaboração de hipóteses sobre o significado dos numerais escritos, há o apoio fundamental em noções de transcodificação oral e escrita na seqüência dos numerais, conforme hipóteses aditivas presentes na compreensão do valor posicional dos algarismos (Sinclair \& Scheuer, 1993; Sinclair, Tièche-Christinat \& Garin, 1994).

Para as autoras citadas, ao se construir na escola um conceito da aritmética, a notação correspondente deve ser trabalhada conforme a seguinte diretiva: as marcas espontâneas das crianças devem ser compreendidas e seguidas para, a partir delas, ser provocada a produção de outras, mais avançadas, sempre segundo os esquemas de interpretação das próprias crianças. O caminho a seguir deve ser então o da figuração em desenho antes da escrita formal, a menos que a criança expresse esta por si mesma, significativamente (H. Sinclair, 1988).

Essa posição responde à questão do tão freqüente confronto e divórcio entre as elaborações matemáticas próprias das crianças e as formas convencionais escolares de representação dos conceitos matemáticos (Ex.: Carraher, Carraher \& Schliemann, 1989).

Importante amostra de idéias sobre o ensino dos sistemas de representação da matemática vem das intervenções feitas em simpósio do CIRADE (Centre Interdisciplinaire de Recherche sur l'Apprentissage et le Développement en Éducation, da Universidade do Québec) (Janvier, 1987). Autores como Lesh, diSessa, Janvier, Kaput, Bélanger, Mason, Goldin, Dufour-Janvier, Bednarz realçam o trabalho escolar com os sistemas representacionais diversificados da matemática, destacando-lhes os benefícios. Entretanto, também apontam a necessidade de ser considerado o que os sistemas de representação significam para os alunos, dado que a construção por estes desses vários sistemas é a meta essencial.

Outros trabalhos sobre o aprendizado da numeração escrita mostram que crianças muito pequenas, de ambientes culturais estimulantes, antes do ensino escolar dominam lexicalmente os nomes dos números (Gelman \& Meck, 1991) muitas vezes sem dominar a significação do número.

Notações próprias de crianças escolarizadas na formulação e solução de problemas de adição e subtração foram identificadas (Schubauer-Leoni \& Perret-Clermont, 1980, 1984). E, entre nós, Selva e Brandão (2000) descreveram notações, de diversos tipos, de pré-escolares do Recife na solução de problemas de subtração, frisando o apoio dessas produções ao pensar infantil e ao avanço no registro de tais operações.

Muitas vezes, porém, crianças escolarizadas lidam com os numerais sem compreendê-los, pois sua experiência não se refere a dimensões inerentes ao sistema da escrita numérica, como a recursão, a estrutura multiplicativa do sistema, o valor posicional dos algarismos escritos (Perret, 1985; H. Sinclair \& A. Sinclair, 1986; Sinclair \& cols., 1994).

Diferentes estudos oferecem a análise de obstáculos, dificuldades e resistências do processo infantil de compreensão do sistema da numeração oral e escrita, em especial no que concerne à idéia de valor posicional. Por exemplo:

- $\quad$ a identificação de três principais dificuldades de alunos de $1^{\text {a }}$ a $4^{\mathrm{a}}$ séries em dominar aquele sistema de escrita: compreensão do valor posicional dos algarismos; uso do símbolo do zero, como mantenedor de posição; uso dos sinais de pontuação (vírgulas e pontos) (Higino, 1997). - a persistência de crianças de idade escolar em seguir vendo o signo numérico para dezenas além de 20 como algo absoluto. Mesmo após lições sobre valor posicional, não recorrem a noções de agrupamento e reagrupamento de base de cada algarismo (Brun, Giossi \& Henriquès, 1984; Kamii \& DeClark, 1985); e seguem com erros lexicais e sintáticos em tarefas de transcodificação de números, por conta da generalização inadequada de regras construídas para casos típicos (Seron, Deloche \& Noël, 1991).

- a apreensão global do significado notacional de certos numerais por crianças de seis anos (genebrinas e argentinas). Mas, para compreender o valor posicional dos algarismos, tentam coordenar três idéias: os dígitos em numerais multidígitos mantêm seu significado em combinações possíveis; o sistema tem características aditivas; a posição ordenada tem papel importante na definição do valor (Sinclair \& Scheuer, 1993).

- o avanço de escolares na construção do sistema da numeração escrita quando compreendem o papel dos "nós" (as potências de base 10,100,1000) antes da escrita dos numerais dos seus intervalos. Logo, a numeração falada intervém na compreensão da escrita numérica e vice-versa, quando algumas hipóteses infantis originais sobre essa escrita podem ser identificadas (Lerner \& Sadovsky, 1996). Na superação de tais hipóteses, ocorre a re-significação da relação entre a escrita dos "nós" e a dos números entre eles posicionados, na aproximação à essência posicional do sistema atual de escrita numérica (ver, também, Lerner de Zunino, 1995).

As diversas dificuldades no processo infantil de compreensão do sistema da numeração oral e da escrita são assim sintetizadas por Teixeira (1996): a) o fenômeno da mudança da unidade; b) a manipulação e elaboração de agrupamento de agrupamentos; c) a língua em termos de sistema de palavras que traduzem os nomes dos números; d) os sistemas representativos usados pelos alunos em sua diversidade e desarticulação como sistemas do campo da experiência escolar e da não escolar. 
Ainda Teixeira (2001), considerando que as relações entre representações internas e externas são cruciais no estudo da compreensão conceitual na matemática, mostra que alunos de $3^{\mathrm{a}}$ e $4^{\mathrm{a}}$ séries do nosso ensino fundamental têm dificuldades típicas de aprendizagem da numeração escrita. Elas seriam ligadas à ênfase inadequada do ensino na apreensão conceitual da idéia de agrupamentos aditivos ou multiplicativos do sistema de numeração, e na sua representação padrão. Para a autora, essas duas dimensões devem ser trabalhadas ao mesmo tempo na escola porque a apreensão conceitual e a representação semiótica são processos inseparáveis.

Por seu lado, Orozco-Hormaza (2002), em alunos colombianos das séries iniciais do ensino fundamental, examina se, na relação entre expressões numéricas verbais e a escrita de numerais no ensino, as regras que regem a notação numérica arábica estão mais ligadas a características morfossintáticas das expressões numéricas verbais, a características operatórias ou ao valor posicional do sistema de numeração. Seus resultados, mostrando erros coincidentes e universais das crianças, levam-na a propor que os erros sintáticos são erros de construção típicos de crianças que ainda não dominam as regras do sistema de notação numérica; mas os erros léxicos vêm de falhas da memória de trabalho, presentes quando as crianças já construíram aquelas regras.

Em síntese, conforme a literatura, poucas dúvidas há sobre o importante lugar da compreensão dos sistemas notacionais na aprendizagem dos conceitos matemáticos. Também há forte demonstração para a idéia de que esses sistemas de notação matemática, um produto cultural, são objetos de conhecimento que as crianças constróem de forma complexa, elaborando sobre eles hipóteses típicas, as quais fazem sentido pela natureza dos conceitos matemáticos e pelas características culturais próprias daqueles sistemas de representação.

Segundo tais perspectivas, configurou-se nosso interesse teórico e pedagógico em analisar a natureza e a transformação das notações das crianças referentes à construção das relações aditivas em sua passagem para as multiplicativas, como uma dentre as diversas formas de examinar as relações psicogenéticas entre esses campos conceituais. Dessa forma, também tivemos a ocasião de avaliar se as tarefas de aprendizagem escolhidas trazem à tona e provocam tais construções conceituais em alunos de séries iniciais da escola fundamental.

Porém, por que escolher tarefas de igualização de parcelas e de repartição grandezas para as crianças?

Em consonância com a teoria dos campos conceituais de Vergnaud (1990, 1991, 1994), e atendendo aos objetivos da investigação, igualar-desigualar parcelas e repartir grandezas foram vistos, em primeiro lugar como esquemas próprios à elaboração de relações aditivas e multiplicativas; em segundo lugar, suas transformações forneceriam sinais das raízes das estruturas multiplicativas nas aditivas, ao serem especialmente trabalhadas, nas tarefas, a composição e a decomposição de uma totalidade em partes equivalentes e/ou não equivalentes, um invariante pensado como inerente à interligação das estruturas em foco.

A assinalar que, ao igualar-desigualar parcelas, adicionar tais parcelas e/ou avaliar-lhes a diferença, a criança pode colocar em jogo algumas das relações, dentre as que, para Vergnaud (1985, 1989-1990, 1990), levam à solução de diversos tipos de problemas aditivo-subtrativos. Seriam tais relações, no caso: a composição de duas grandezas em uma terceira; a transformação quantificada de uma grandeza inicial em uma final; a comparação quantificada entre duas grandezas.

É a própria literatura piagetiana (Piaget \& Szeminska, 1971; Piaget, 1977; Piaget, 1996) que aponta resultados expressivos a respeito da fecundidade do igualar-desigualar coleções quantitativas para inferências e deduções de crianças pequenas, e que envolvem outros esquemas e relações essenciais ao domínio ainda aritmético de adições-subtrações como sistema de operações inversas. São exemplos, os esquemas de correspondência biunívoca, de acréscimodecréscimo reiterado um a um de elementos, de contagem ordenada, os quais permitem a elaboração de inferências lógico-matemáticas características, tais como: a iteração, a comutatividade, a recorrência, a conexidade.

Por outro lado, é conhecida a ampla literatura sobre o quanto o repartir coleções é precoce no repertório das realizações infantis, ainda que em formas muito elementares, o que tem alimentado as discussões sobre as origens da divisão (Correa, 1996; Correa, Nunes \& Bryant, 1998; ParratDayan, 1980, 1985).

Se repartir coleções (mediante estratégias variadas e originais, muitas vezes apoiadas em relações aditivas) é considerado relativamente fácil para as crianças, tem sido demonstrado que é complexo, para elas, discriminar e compreender as relações específicas da divisão, propriamente dita (Kornilaki \& Nunes,1999; Nunes \& Bryant, 1997; Squire, Bryant \& Correa, 1999).

Vergnaud $(1985,1998)$ refere-se, especialmente, aos diversos tipos de dificuldades das crianças na compreensão da divisão envolvendo elementos discretos e/ou números inteiros, no contexto das estruturas multiplicativas, entre as quais, a necessidade de efetuar-se cálculos relacionais diferentes: procurar e obter a extensão da parte (valor unitário de mesma medida) conforme o valor escalar indicado, no caso da divisão por partição; ou procurar e obter o número de partes (a quota) conforme sua extensão indicada, o caso da divisão por "quota".

Há indicações interessantes de que a divisão por partição é, nos seus inícios, menos difícil para as crianças. Squire e 
Bryant (2002), por exemplo, apontam menor dificuldade na obtenção do quociente quando o dividendo aparece às crianças (em desenho de elementos) agrupado pelo divisor em divisão por partição, e pelo quociente em divisão por quota, em comparação com o inverso (agrupar pelo quociente em divisão por partição, agrupar pelo divisor em divisão por quota). Isto ocorreria por apoiar-se a criança no esquema de fazer "porções" ao repartir, o que seria psicologicamente diferente conforme os dois tipos de problemas.

Em suma, essas proposições são as que nos fizeram escolher, para este estudo, as tarefas de igualização de parcelas desiguais, e a de repartição de grandezas com problemas do tipo divisão por partição (dado o dividendo e o divisor, descobrir a extensão da parte).

\section{Método}

Os participantes do estudo foram 12 alunos (de 6,4 a 9,5 anos de idade), de duas escolas públicas de municípios diferentes, sendo seis de $1^{a}$ série e seis de $2^{a}$ série do ensino fundamental. Estas escolas localizam-se na periferia urbana de duas grandes áreas metropolitanas.

Por conta de o projeto de investigação em que este estudo está inserido também voltar-se ao exame das formas de trocas sociais infantis durante a realização das tarefas (dimensão esta não aqui abordada, por causa da necessária delimitação deste texto), os participantes foram agrupados em tríades por sorteio aleatório. Esse sorteio para a composição das tríades seguiu o critério da defasagem ótima (Doise \& Mugny, 1981). ${ }^{3}$

As tarefas oferecidas podem ser caracterizadas como situações-problema de conteúdo aritmético. Propostas oralmente pelo pesquisador para solução conjunta dos componentes das tríades segundo estratégias próprias de cada um deles, as tarefas ocorreram, conforme acima justificado, em ciclos alternados de: solução prática com apoio no material com interpretação simultânea e final do executado; produção de notações e interpretação das notações produzidas. Este ciclo foi cumprido por três vezes (as "rodadas") tanto para as tarefas de igualização com para as de repartição.

As intervenções do pesquisador em todos os momentos foram pautadas pela necessidade de: orientar as crianças na compreensão do que o problema pedia ("... vejam, os dois bonecos têm que ficar com o mesmo tanto igual de fichas...”);

\footnotetext{
${ }^{3}$ Para cumprir o critério da defasagem ótima (grau próximo de heterogeneidade entre os participantes, necessário para haver confronto de pontos de vistas em um pequeno grupo), foi feita uma classificação prévia dos alunos das séries indicadas e de cada escola em três níveis de avanço cognitivo em noções ligadas aos conceitos trabalhados nas tarefas (conservação de quantidades numéricas, inversão adição/ subtração, composição aditiva de números).

desafiar mediante perguntas as soluções incompletas ou menos avançadas para a busca de outras soluções (“... e será que assim estão todos com o mesmo tanto igual de fichas?”); intermediar as diferentes soluções expressas pelas crianças para provocar-lhes alterações e reinterpretações das realizações de uma e outra delas ("... olhem vocês ali, o que La desenhou, será que pode também ser assim?...”). Nos trechos de protocolos expostos na parte de resultados, outros exemplos dessas formas de intervenção podem ser identificados.

O material utilizado consistiu de: uma coleção de 18 fichas de plástico (mesma cor), uma caixa com uma divisória repartindo-a em duas metades, dois bonecos, folhas de cartolina, canetas hidrocor. As crianças podiam nomear os elementos conforme suas próprias interpretações dos problemas, por exemplo: fichas, balas ou bolachas para os dois bonecos, ou para serem repartidas "entre vocês três".

As tarefas centradas na igualização de coleções (primeira sessão) pediam especificamente:

- a composição e identificação de duas parcelas, não equivalentes, de uma adição, obtidas ao acaso pelas crianças, em sua vez ("rodada"), sendo seu total limitado a 16 elementos, seguida da identificação da extensão da diferença. Por exemplo: para parcelas de 11 e 7 elementos “... é para descobrir quantas balas têm para cada boneco...", e “... descobrir quantos este (boneco) tem a mais.., ou a menos que o outro...".

- a igualização, sem referente, das duas parcelas desiguais identificadas. Por exemplo: para parcelas de 11 e 7 elementos “... agora, o que vocês vão fazer para os dois bonecos ficarem com a mesma quantidade igual de balas?...", “ ...por que ficou a mesma quantidade?" (Piaget,1996; Piaget \& Szeminska, 1971).

Entre cada um desses momentos, as crianças eram convidadas a “...marcar, desenhar, escrever com números, do jeito que vocês quiserem ..." na cartolina única "... o que aconteceu com as balas do boneco..., o que vocês fizeram antes com as fichas.". Após fazer as notações, as crianças eram convidadas a interpretar suas produções: “... o que você quis dizer quando marcou isto?...", "por que você marcou assim?".

As tarefas centradas na repartição consistiram em recompor uma coleção de fichas em duas partes iguais na segunda sessão, e em três (as três crianças) e quatro partes iguais (as crianças e o pesquisador) na terceira sessão. A extensão numérica das coleções, escolhida ao acaso por cada criança na sua vez (a "rodada"), limitava-se a 18 elementos. Eis o tipo de instrução dada pelo pesquisador: “... escolha, sem ver, muitas fichas (ou "bolachas"), para repartir entre os dois bonecos...", ou "... para repartir entre vocês três..., entre nós quatro...”. As crianças eram solicitadas a interpretar cada repartição obtida: "Vejam... por que ficou assim?..., o que aconteceu agora?”. E, também a cada repartição, eram 
convidadas a produzir notações a respeito do que fora obtido e interpretar a respectiva notação produzida: 'Marquem, agora, como vocês quiserem, o que o Juc fez, o que aconteceu quando ele repartiu as fichas..."; "por que você marcou isto assim?..., "...o que você quis dizer com este desenho?".

O registro dos dados ocorreu pela gravação em vídeo e a posterior transcrição, para cada tríade, de todos eventos gravados (ações, verbalizações das crianças e do adulto) de toda a seqüência das tarefas.

A análise dos dados, de ordem qualitativa e microgenética, foi realizada, primeiro, com a identificação das características centrais das notações produzidas e das interpretações das crianças sobre elas; depois, com a descrição, em categorias principais, dos tipos de notação tal como interpretadas pelas crianças, segundo sua significação no processo de elaboração estudado (Gardin, 1974; Gillièron, 1980). Para tanto, recorreu-se a indicadores oferecidos por alguns dos autores de referência já indicados neste texto. Por exemplo, de Vergnaud (1985, 1989-1990, 1990) relações entre estado inicial, transformação e estado final em problemas aditivo-subtrativos; de A. Sinclair (1990) a tipologia de notações infantis para coleções de extensão reduzida.

\section{Resultados}

Nos três itens que seguem, descrevemos os diferentes tipos de notações interpretadas que encontramos, agrupados em suas categorias: no primeiro item, as notações produzidas quando da composição e identificação das duas parcelas não equivalentes de uma adição; no segundo item, as notações de igualização das parcelas não equivalentes; e no terceiro, as notações produzidas quando da repartição das coleções em 2,3 e 4 partes iguais.

Nesses três itens, e para cada categoria, os tipos de notação são descritos dos menos aos mais avançados, conforme a avaliação qualitativa deles efetuada como expressão das relações aritméticas trabalhadas com o material, sempre levando em conta as interpretações que seu autor fez sobre sua notação. ${ }^{4}$

A. Notações de composição identificada de duas parcelas não equivalentes de uma adição

1. Desenhos de uma ou mais coleções de elementos, representando:

a) o total, não equivalente ou equivalente ao composto pelas parcelas trabalhadas, por vezes com acréscimo

\footnotetext{
${ }^{4}$ Cada exemplo de notação é identificado conforme a tríade da série escolar (tríade $1^{\mathrm{a}}$ ou $2^{\mathrm{a}}$ ), a inicial do nome do município de localização da escola (P ou S), a sessão de trabalho $\left(1^{\mathrm{a}}, 2^{\mathrm{a}}\right.$ ou $\left.3^{\mathrm{a}}\right)$ e a rodada da tarefa em que foi produzida $\left(1^{\mathrm{a}}, 2^{\mathrm{a}}\right.$ ou $\left.3^{\mathrm{a}}\right)$. Nos exemplos, a abreviatura expindica intervenções do experimentador.
}

posterior, pertinente ou não, de um elemento como parcela. Por exemplo:

- tríade $1^{\mathrm{a} S}, 1^{\mathrm{a}}$ ses., $2^{\mathrm{a}}$ rod., para parcelas de 3 e 6 fichas, Ade (desenha 9 fichas, adiante 1 ficha): "...coloquei nove.”(apontando coleção desenhada); exp: "Marcou cada parte ou marrou tudo?"; Ade: "Tudo, ... este não..." (aponta desenho de 1 ficha).

b) as duas parcelas, equivalentes às parcelas antes compostas, em geral reconhecidas como mais e menos numerosas, anunciados seus valores numéricos. As seguintes formas de controle são usadas durante sua produção: contagem unitária, emparelhamento de elementos, sub-parcelamento das parcelas mais numerosas $(10,11)$. Por vezes, é identificada a extensão da diferença entre as parcelas; mas, excepcionalmente, é apontada a redistribuição eqüitativa dessa diferença para igualizar as parcelas, com exclusão de elemento restante. Por exemplo(Figura 1):

- tríade $2^{\mathrm{a}} \mathrm{S}, 1^{\mathrm{a}}$ ses., $2^{\mathrm{a}}$ rod., para parcelas de 11 e 2 fichas, após Jes apontar 11-2=9, exp: "Quantas fichas deste lado (desenho de 11) tiveram que vir para este lado (desenho de 2), pra ficar 6 e 6?"; Dei (mão em cima de 4 desenhos dos 11, logo, 11- 4): "Quatro."; exp: "É isto mesmo? Pra ficar seis do outro lado?"; Dei: (acena sim); exp: "E quantas vão ficar do lado de lá? (em 11- 4)"; Dei: "Sete."; exp: "Sete e sete?"; Jes: "Dois."; Dei: "Seis" (desenho de parcela 2+4=6); exp: "Sete e seis? E dai, era a mesma coisa dos dois lados?"; Jes: "Não."; Dei: "Não... tem que tirá um $(7-1=6)$...".

2. Algarismos:

a) traçados em duas seqüências, cada uma no limite da extensão de cada parcela. Cada algarismo representa um elemento das parcelas. Por exemplo:

- tríade $1^{\mathrm{a}} \mathrm{S}, 1^{\mathrm{a}}$ ses., $2^{\mathrm{a}}$ rod., para parcelas de 3 e 6 fichas, Flo (traça 1,2,3, depois 1,2,3,4,5,6), exp: "Por que botarestes números?”; Flo: “Éporque 3 e 6 chocolates...”(apontando cada algarismo da primeira e da segunda seqüência).

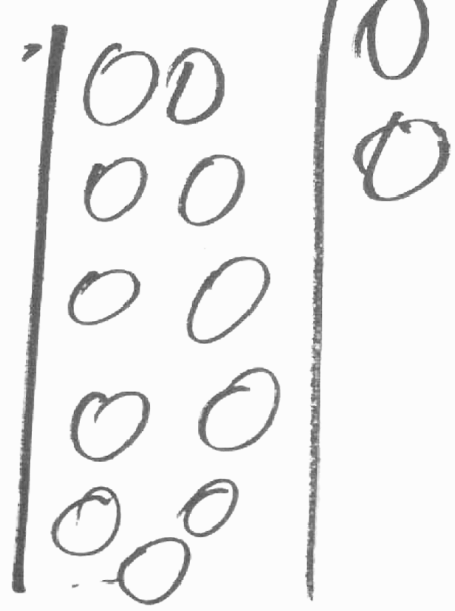

Figura 1. As parcelas desiguais 11 e 2 . 
b) traçados de dois numerais, em separado, cada um correspondente à extensão cardinal de cada parcela. Por exemplo:

- tríade $2^{\mathrm{a}} \mathrm{S}, 1^{\mathrm{a}}$ ses., $2^{\mathrm{a}}$ rod., para parcelas de 11 e 2 fichas, Eve (traça 11 e 2, em duas caselas) “...porque é onzę e dois.”

B. Notações de igualização de duas parcelas de uma adição

1. Desenhos de uma ou mais coleções de elementos, representando:

a) o total, não equivalente ou equivalente ao composto pelas parcelas trabalhadas, sem e com elemento restante. Por exemplo:

- tríade $1^{\mathrm{a}} \mathrm{P}, 1^{\mathrm{a}}$ ses., $1^{\mathrm{a}}$ rod., para parcelas de 5 e 4 fichas, Luh (desenha 8 fichas) "...é tudo junto."; (desenha mais 3 abaixo e 1 ao lado das 8, em outra cor); Jef (sobre desenho de Luh): "É o resto.".

b) duas parcelas não igualizadas, mas vistas apenas em seu total, este tornado equivalente ao total trabalhado mediante marca de exclusão de elemento. Por exemplo:

- tríade $1^{\mathrm{a}} \mathrm{P}, 1^{\mathrm{a}}$ ses., $3^{\mathrm{a}}$ rod., parcelas de 5 e 5 fichas, Jef (desenha 4 fichas; em separado e alinhadas, outras 7 fichas, aponta-as todas, risca uma ficha das 7, aponta todos os desenhos) "Der.... tudo".

c) duas parcelas não igualizadas, a mais numerosa vista como equivalente à primeira por correspondência global/ espacial. Seu total, não equivalente ao trabalhado, é avaliado como tal. Por exemplo (Figura 2):

- tríade $1^{a} \mathrm{P}, 1^{a}$ ses., $1^{a}$ rod., para parcelas de 4 e 4 fichas em total de 9 fichas, Jef (desenha 4 fichas grandes alinhadas; acima, desenha 5 fichas menores, alinhando-as nos extremos do espaço com as 4 anteriores; desenha mais uma ficha em espaço vazio, parcela = 6): "...tá igual." (conta todos os desenhos...): "Nove.".

d) duas parcelas igualizadas, de extensão não correspondente à das parcelas trabalhadas, mas cuja adição eqüivale à do

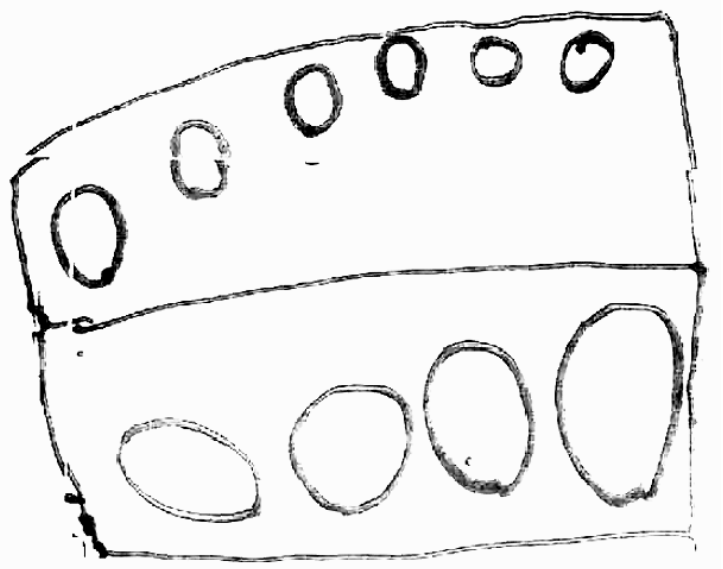

Figura 2. As parcelas igualizadas 6 e 4. total original, conforme marcado por algarismo "etiqueta" e assim interpretado. Por exemplo (Figura 3):

tríade $2^{\mathrm{a}} \mathrm{P}, 1^{\mathrm{a}}$ ses., $3^{\mathrm{a}}$ rod., para parcelas de 3 e 3 fichas, Ann (desenha 5 e 5 fichas e escreve 6 ao lado) "...vou colocá seis em tudo." [...]; exp: (apontando desenhos de Ann): "Aqui tem seis?"; Ann (aponta desenhos): "Tem que tirá dois. (risca 2 desenhos de cada lado); exp: "Por que será que ela (Ann) tirou dois de um lado e dois do outro?"; Ju: "Pra ficá seis". Exp: "E dai, quantos ficou em cada parte?"; Ju: "Três." Ann: "Três..." (desenha uma ficha na $4^{a}$ parcela, $6+1=7$, risca este desenho e o algarismo 6).

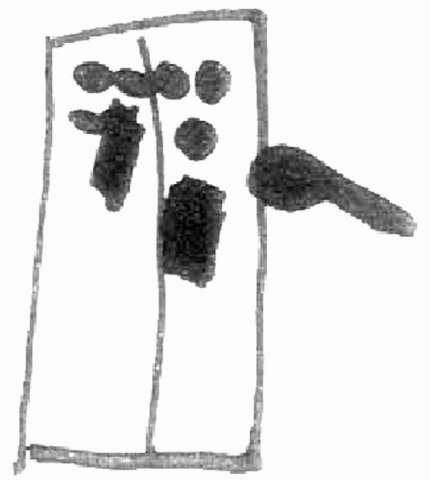

Figura 3. A igualização das parcelas 3 e 3.

e) parcelas igualizadas cuja adição é o dobro do total trabalhado mediante:

(1) duplicação do número de parcelas (quatro) de extensão equivalente às igualizadas, com aceitação das parcelas excedentes. Por exemplo:

- tríade $2^{\mathrm{a} S}, 1^{\mathrm{a}}$ ses., $1^{\mathrm{a}}$ rod., para parcelas de 6 e 6 fichas, Jes (em separado, desenha 6 e 6 fichas, mais 6 e 6 fichas) “...seis de um lado, seis de outro..."(aponta duas parcelas de 6); exp: "E estes daqui... (sinal para outras parcelas de 6) você marcou de novo? "' Jes: "É... tinha mais.".

(2) duplicação da extensão de duas parcelas, cada uma equivalente ao total. São vistas, depois, como excedendo a extensão das parcelas originais. Por exemplo:

- tríade $2^{\mathrm{a}} \mathrm{S}, 1^{\mathrm{a}}$ ses., $1^{\mathrm{a}}$ rod., parcelas de 6 e 6 fichas, total de 13 fichas, Dei (desenha 12 fichas, faz traço de separação e desenha mais 12 fichas emparelhadas) "...doze e doze... (apontando cada linha de 12); exp: "Doze em cada lado?"; Dei: "Não!...demais...”;“...eram seis?”.

f) duas parcelas igualizadas, equivalentes às trabalhadas, sem e com desenho de elemento restante quando é o caso. São vistas como resultado da igualização, sendo excepcional a evocação das ações aditivas e/ou subtrativas que levaram àquele resultado. As seguintes formas de controle são usadas em sua produção: contagem unitária, emparelhamento de elementos, sub-parcelamento das parcelas mais numerosas. Por exemplo: 
- tríade $1^{\mathrm{a} S}, 1^{\mathrm{a}}$ ses., $1^{\mathrm{a}}$ rod., para parcelas de 5 e 5 fichas em total de 11 fichas, Flo (desenha, alinhados, 5 e 5 traços...) (adiante, olhando Eri, que desenha uma ficha à parte...); Flo (afastado, faz um traço): “É cinco e cinco."; exp: "Para os dois bonecos?"; Flo (aceno afirmativo); exp: "Como foi que ferz?"; Flo (silêncio); exp: 'E este?”(traço à parte); Flo: “É a sobra.”.

g) de duas parcelas desiguais, o estado inicial das parcelas trabalhadas, e que têm sua igualização representada por:

(1) marcas de subtração do excedente de uma das parcelas, identificado como resto. Por exemplo (Figura 4):

- tríade $2^{\mathrm{a}} \mathrm{P}, 1^{\mathrm{a}}$ ses., $2^{\mathrm{a}}$ rod., para parcelas de 5 e 5 fichas, antes de 6 e 5 fichas, Ju (desenha 6 e 5 fichas, "borra" desenho de uma ficha em um lado, aponta tudo): "Cinco e cinco, ... é como era no comeco...".

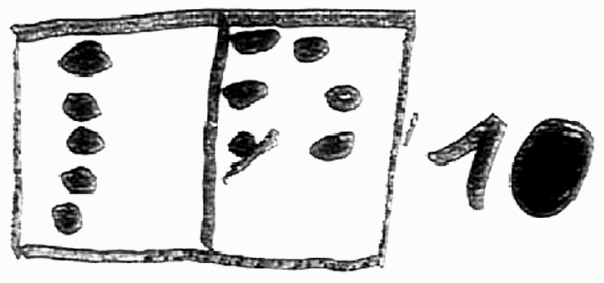

Figura 4. A igualização das parcelas 6 e 5 .

(2) traçado delimitador, na parcela mais numerosa, para a diferença em relação à parcela menos numerosa, antecedido por gestos. Aquela diferença é vista como diferença absoluta a subtrair de uma parcela ou como diferença a distribuir entre as parcelas. Por exemplo: tríade $2^{\mathrm{a} S}, 1^{\mathrm{a}}$ ses., $3^{\mathrm{a}}$ rod., para parcelas de 5 e 5 fichas, antes de 7 e 3 fichas, exp (para desenho de 7 e 3 fichas de Dei e Jes: "Quantas têm que passar para ficar mesmo tanto igual?"; Dei (aponta cada desenho da parcela $=3$, levanta 3 dedos, aponta 3 desenhos na parcela $=7$ e os 3 parcela $=3$, cobre com dedos os 3 da parcela $=7$, aponta 3 desenhos parcela $=3$, levanta um dedo e o põe em cima de um elemento da parcela=4; "segura" com 2 dedos, 2 desenhos dos 4 separados; e aponta com caneta 3 desenhos da parcela $=3$, abaixo, e 1 desenho acima, deixa mão em cima de 7 desenhos); Jes: “Tirando quatro.”; exp: "Tirando quatro... de qual lado épra tirar quatro?”; Jes (aponta parcela $=7$, faz traço de separação de 4 desenhos da parcela $=7$, aponta 3 desenhos da outra parcela): 'Um, dois três, os quatro."; exp: "Fica quantidade igual se tirar quatro daquele lado? Vejam."; Dei (aponta 4 desenhos da parcela $=7$ ) "...é certo." (faz traço contornando 4 desenhos e aponta cada um); "Quatro."; exp: "Quatro, tira? E põe junto com qual?”; Jes: “Com este." (aponta desenho parcela
=3); exp: "E daí, dá pra ficar a mesma quantidade?"; Jes: "Não, daí (com gesto) tem que pôr um de um lado, um de outro."; $\exp$ (apontando desenho parcela=7 de Dei): “... mas dápra descobrir aqui, quantos tem que sair daqui (apontando cada parcela) pra irpara lá?"; Dei: “Quatro."(aponta 4 e 3 desenhos); exp: "Quatro, mesmo? De outro jeito não dá para fazer? "; Dei: (aponta cada parcela desenhada, uma a uma e faz aceno negativo).

\section{Algarismos:}

a) traçado repetido (duas vezes) de numeral correspondente não a cada parcela trabalhada, mas ao total resultante da adição de ambas. São interpretados como cardinais das parcelas, o que leva à rememoração da extensão das parcelas originais, com decorrente indicação de excedente em ambas. Por exemplo:

- tríade $2^{\mathrm{a} S}, 1^{\mathrm{a}}$ ses., $2^{\mathrm{a}}$ rod., para parcelas de 6 e 6 fichas, Eve (traça 12 e 12 em separado); (...); Jes: “...tinha doze? Não! Tinha seis de um lado e seis de outro."; exp: "Quando vocês marcaram doze, não era tudo o que tinha na caixa"; Eve: "Era.".

b) traçados como "etiqueta" de desenhos de duas parcelas, visto como resultado da adição das mesmas e com sentido cardinal. Por exemplo:

- tríade $2^{2} \mathrm{P}, 1^{\mathrm{a}}$ ses., $3^{\mathrm{a}}$ rod., para parcelas de 3 e 3 fichas Le (para desenhos de 3 e 3 fichas escreve, em "espelho", 6 acima; aponta cada desenho): "É em tudo...".

A análise das notações descritas mostra, primeiro, a ausência de relação hierárquica entre as duas categorias principais encontradas, desenhos e algarismos, considerado o critério de significação das relações aditivo-subtrativas trabalhadas quando de sua produção e interpretação.

Tendências específicas de construção das referidas relações podem ser constatadas nas produções descritas em cada categoria. São elas:

- do registro de estados (inicial e final) para o de transformações aditivo-subtrativas efetuadas sobre as coleções (Vergnaud, 1985, 1989-1990).

- do registro de coleções totais, não parceláveis, para o de parcelas deste total, as quais são adicionáveis conforme a idéia de uma transformação efetuada nas parcelas originais (estado inicial) resultando em um total, o estado final.

- do registro de adição de parcelas equivalentes para o de adição de parcelas não equivalentes. É a presença predominante da idéia da simetria entre partes de um todo, quando o "resto" da parcela é excluído (parcelas simétricas é que são adicionáveis), que se altera para a de assimetria das parcelas de uma adição. Quando parcelas não equivalentes (assimétricas) podem ser, então, adicionáveis, ocorre, sobretudo, a adição à parcela mais 
numerosa dos elementos da menos numerosa, um a um (por counting on first, segundo Baroody \& Ginsburg, 1986).

- da idéia, ainda predominante, de que elementos excedentes de uma parcela devem ser subtraídos na igualização, mas não acrescentados à outra parcela, na recomposição das quantidades mediante transformações coordenadas +1 , -1 (da exclusão de elementos das parcelas para a sua inclusão por redistribuição). Logo, é excepcional a idéia de que a igualização das parcelas decorre de transformações aditivo-subtrativas de elementos de estados iniciais (as parcelas não igualizadas), do que somente um caso foi encontrado: Ju $\left(2^{\mathrm{a}} \mathrm{P}, 1^{\mathrm{a}}\right.$ ses., $1^{\mathrm{a}}$ rod.), de parcelas 6 e 2 faz a adição de 2 fichas da parcela 6 à parcela 2, obtendo parcelas iguais 4 e 4 .

- da atribuição de medidas absolutas, isoladas, às parcelas ("mais", "menos"), com valores absolutos a excluir/ subtrair quando for o caso, para a atribuição de medidas relativas em compensação (decomposição e recomposição de parcelas "a mais", "a menos").

C. Notações de repartição de coleções em 2, 3 e 4 partes

1. Desenhos de coleções de elementos, vistos como:

a) total (dividendo) não equivalente ou equivalente ao trabalhado. Por exemplo:

- tríade $1^{a}$ P, $2^{a}$ ses., $1^{a}$ rod., para $13 \div 3$, Luh (desenha 9 fichas, aponta cada, desenha 4 fichas abaixo, aponta todas); exp: "Por que você fez estas bolinhas?”; Luh (silêncio); exp: "Mas antes você contou estas bolinhas."; Luh: "Treze.."; exp: "Por quê?; Luh: "Porque tinha treze ali".

b) partes da repartição, em número (divisor) e extensão numérica (quociente) não equivalentes às trabalhadas, sem e com resto pertinente. Por vezes, as partes têm extensão conforme a do total (dividendo), duplicando-o (repartição por 2); e/ou têm elementos excedentes "subtraídos" para igualização, mas nem sempre distribuídos/acrescentados à(s) outra(s) parte(s). Formas de controle (contagem unitária, emparelhamento espacial, distribuição um a um de elementos a cada parte, subparcelamento das grandezas) são empregadas no desenho das partes de extensão mais numerosa (acima de 5). Por exemplo:

- tríade $2^{\mathrm{a}} \mathrm{P}, 2^{\mathrm{a}}$ ses., $1^{\mathrm{a}}$ rod., para $12 \div 3$, Ann (desenha em separado 6 e 6 fichas, escreve 12 acima); (...) (quando Ju conta seus 6 e 6 desenhos) Ann: "Nós tiramo dois de cada lado." (riscando 2 desenhos de cada lado de sua notação): "Tirar dois e tirar dois,... tá igual, assim." (para 4 e 4 desenhos de fichas, de cada lado e sem os riscos).

c) partes da repartição em número (divisor) e de extensão numérica (quociente) equivalente às trabalhadas, sem e com resto pertinente. São também utilizadas formas de controle (contagem unitária, distribuição um a um de elementos a cada parte, sub-parcelamento das grandezas) ao serem desenhadas partes de extensão mais numerosa (acima de 5). Por exemplo (Figura 5):

tríade $2^{\text {a }} \mathrm{S}, 3^{\mathrm{a}}$ ses., $1^{\mathrm{a}}$ rod., para $13 \div 3$, Eve (desenha aos pares em separado 4, 4 e 4 fichas, desenha 1 à parte) "... do mesmo jeito, fir quatro, quatro e quatro." (aponta cada parte); exp: "E aqui??"(apontando 1 ficha desenhada); Eve: "Ficou de fora."; exp: "Quatro pra você?"; Eve: "É, e pro Dei e pra Jes.” (aponta cada parte); exp: "Então, em tudo aqui eram quantas?"; Eve: "Eram treze." (gesto para todos os desenhos).

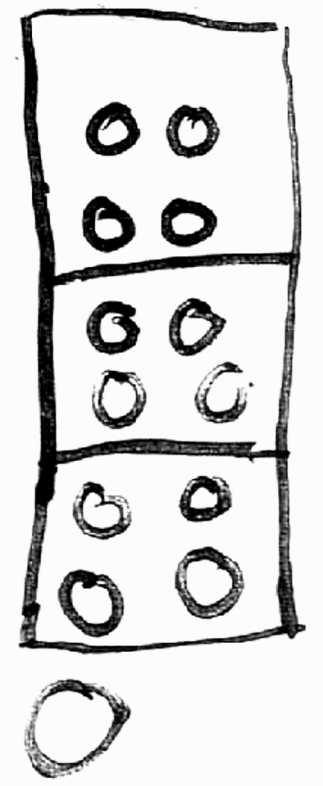

Figura 5 . As partes e o resto para $13 \div 3$.

d) total e, em separado, suas partes, sem e com o resto pertinente. É excepcional algum desenho para o divisor. Por exemplo:

tríade $1^{\text {a }} \mathrm{S}, 3^{\mathrm{a}}$ ses., $2^{\mathrm{a}}$ rod., para $16 \div 3$, Flo (desenha 16 fichas, 5, 5, e 5 traços) “...pus dežesseis.” (apontando desenho de 16 fichas),... (aponta cada linha de 5 traços); exp: "Eram todas as balas que a boneca escolheu?"; Flo: (aceno afirmativo); exp: "E aqui?”" (aponta desenhos de 5 traços); Flo: “Cinco pra cada."; exp: "Quantas crianças tinham para dividir os dežesseis?"; Flo: "Três.".

e) cada um dos termos da divisão trabalhada (dividendo, divisor, quociente e resto) vistos como decorrentes das ações efetuadas. Por exemplo (Figura 6):

tríade $1^{\text {a }} \mathrm{S}, 3^{\mathrm{a}}$. ses., $3^{\mathrm{a}}$. rod., para $15 \div 4$ Eri (desenha 15 fichas, outras 5, aponta cada desenho, risca um desenho, desenha outras 3 fichas); "Eu pus quinze (aponta as 15 
fichas desenhadas) ... foi repartido em quatro." (aponta desenho de 4 fichas e de uma, riscado); exp: "E quantas ficaram para cada um?"; Eri: "Três." (apontando 3 fichas desenhadas): Eri (desenha outras 3 fichas) “...o resto.”.
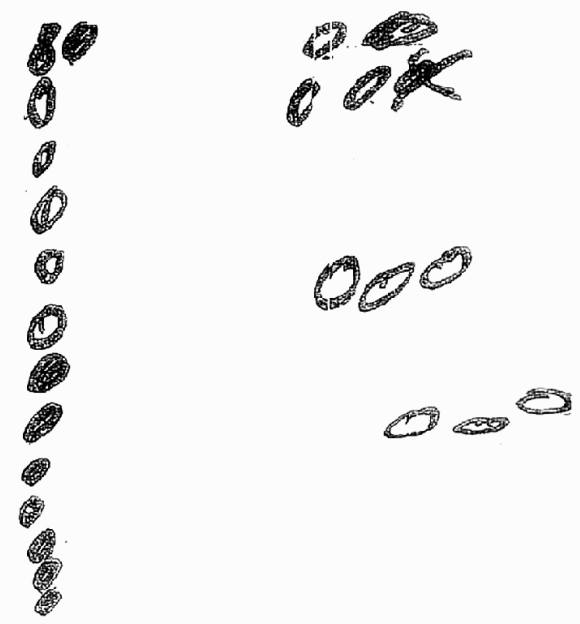

Figura 6. A repartição $15 \div 3$.

- tríade $2^{\mathrm{a} S}, 2^{\mathrm{a}}$ ses., $2^{\mathrm{a}}$ rod., para $10 \div 2$, Dei (para desenho de duas partes de 5 fichas): "Tava dez, depois repartin e ficon cinco pra cada lado." (aponta cada parte desenhada); exp: "Repartiu em partes?"; Dei: "Em duas, dois."

f) total (dividendo) não equivalente ou equivalente ao trabalhado, contendo as partes resultantes da repartição (marcadas no próprio total), sem e com resto pertinente. Por exemplo (Figura 7):

- tríade $2^{\text {a }} \mathrm{S}, 3^{\mathrm{a}}$ ses., $3^{\mathrm{a}}$ rod., para $18 \div 4$, Dei (desenha de 3 em 3, 18 fichas, apontando fichas, traça linha contornando cada 4 desenhos, de cima para baixo e ao lado; após Eve, traça 18 ao lado com contorno); exp: "Repartiu dezoito em quantas partes?”; Dei e Jes: “Quatro.”; Dei: “...quatro, quatro,

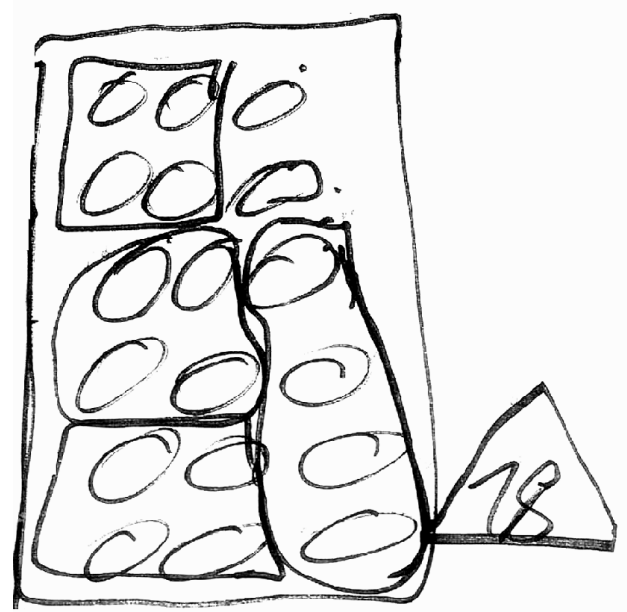

Figura 7. As partes e o resto para $18 \div 4$. quatro e quatro..." (apontando cada parte no desenho) ...e sobrou dois (aponta 2 fichas desenhadas).

2. Algarismos:

a) traçado, em sentido inverso, mas na ordem convencionada, de duas seqüências de numerais, separadas, às vezes misturando-os com outros sinais. Cada seqüência tem limite dado pela extensão da parte obtida da repartição, com cada traçado representando um elemento. Por exemplo (Figura 8):

- tríade $1^{a} \mathrm{P}, 1^{\mathrm{a}}$ ses., $1^{\mathrm{a}}$ rod., para $12 \div 2, \mathrm{Br}$ (da direita para a esquerda escreve 1,2,3,5,6,6, adiante 1,2,3,4,5,6, desenha estrela entre as duas séries) "... seis de um lado, seis de outro."

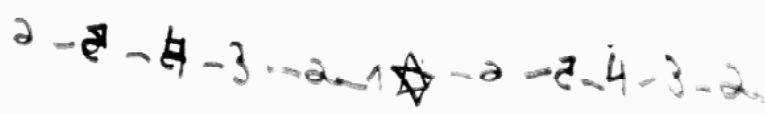

Figura 8. São 12 repartidos por 2.

(aponta cada algarismo, escreve 4 e 5 em cima de 5 e 6 , em uma das séries).

b) traçado de numeral como "etiqueta" das quantidades desenhadas, as partes obtidas e/ou o total resultante de sua adição. Nem sempre corresponde à extensão numérica das quantidades desenhadas, embora conforme ao total trabalhado com o material. Por exemplo (Figura 9):

- tríade $2^{\mathrm{a}} \mathrm{P}, 2^{\mathrm{a}}$ ses., $3^{\mathrm{a}}$ rod., para $12 \div 4$, Le (escreve 3 acima de cada uma das quatro partes de 3 desenhos, e 6 , abaixo, para duas partes juntas) “... em tudo doze.”"; exp: "E você
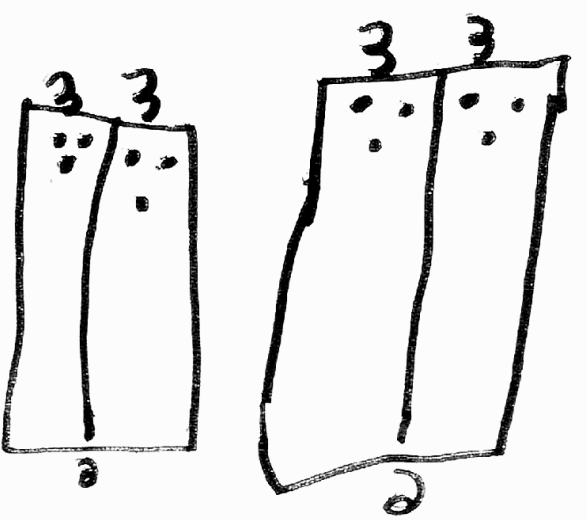

Figura 9. As quatro e as duas partes para $12 \div 4$.

dividin em quantaspartes?"; Ju e Le: "Três."; exp: “Trêspartes?”; Le: 'Não! Quatro (aponta cada parte.").

c) traçado de numerais em expressão aditiva canônica em duas parcelas de mesma extensão, esta correspondente à das partes obtidas. Após leitura aditiva tradicional para a expressão, somente a rememoração do adulto faz o sujeito ali descrever as partes da repartição antes efetuada. Por exemplo: 
- tríade $2^{\mathrm{a} S}, 2^{\mathrm{a}}$ ses., $2^{\mathrm{a}}$ rod., para $10 \div 2$, Jes (escreve $5+5=10$, abaixo $5+5=10$ ) "...eu fiz a conta... (aponta expressões escritas)... de cinco mais cinco dez:"; exp: "O que você fez com os dez? O que o Dei fez com os dez aquela hora?". Jes: "Ele juntou cinco e cinco..." (aponta cada expressão).

d) traçado repetido e separado de numeral correspondente à extensão das partes, lido como resultado da ação de repartir, sem e com resto pertinente e, por vezes, com numeral para o total repartido. Por exemplo:

- tríade $2^{\mathrm{a}} \mathrm{S}, 2^{\mathrm{a}}$ ses., $1^{\mathrm{a}}$ rod., para $14 \div 2$, Eve (desenha caixa, traça 7 de um lado e 7 de outro) "...que é sete para cada um."; "... tudo junto, quatorze."; exp: "Em quantas partes você dividiu os quatorze?"; Eve: "Duas.”; exp: "E quantos ficaram pra cada boneco?"; Eve: "Sete.”.

\section{Escrita alfabética:}

a) escrita da resposta ao problema trabalhado no formato escolar tradicional, com marca repetida de algarismo, para duas partes, a do próprio sujeito e a do adulto. Contém a idéia de que o resultado do repartir é a extensão numérica da parte de cada um e de apenas alguns dos parceiros da repartição. Por exemplo (Figuras 10a e10b): tríade $2^{\mathrm{a}} \mathrm{P}, 2^{\mathrm{a}}$ ses., $3^{\mathrm{a}}$ rod., para $12 \div 4=3$, Ann (escreve: R:CUANTAS BOLACHAS/SÃO e abaixo, separados, 3 e 3); enquanto Ju (escreve R: CUANTAS BOL $A C H A S$ 33; Le (escreve: R: CUANTAS BOLACHAS/ SÃO); exp: "Quantas bolachas, vocês escreveram ai?"; Ju: "Ahn! Ahn!"; exp: “É a resposta?”; Ann: “Ahn! Ahn!”; exp: “...quantas bolachas, pra quantas pessoas?”; Ann: "Três.”; exp: "Três, o

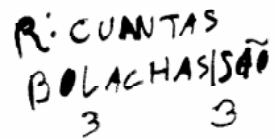

Figura 10a. As duas partes para $12 \div 4$ (de Ann).

\section{R: COANTA BOACHAS33}

Figura 10b. As duas partes para $12 \div 4$ (de Ju).

quêe? "; Ann: "Três pra mim, três pra você." (apontando cada algarismo 3).

b) do nome do numeral correspondente à extensão da parte obtida, visto como tal, e repetido conforme número de partes. Por exemplo:

- tríade $2^{\mathrm{a}} \mathrm{S}, 2^{\mathrm{a}}$ ses., $1^{\mathrm{a}}$ rod., para $14 \div 2$, Jes (escreve sete, traça linhas de separação, escreve sete) "... sete e sete... porque era sete."

Consideradas as três categorias de notação de repartição obtidas, desenho, algarismo e escrita alfabética, temos um resultado diferente do ocorrido com as notações das parcelas não igualizadas/igualizadas no que concerne a alguma hierarquia entre elas. Assim, conforme o critério do significado do repartir expresso quando da produção e da interpretação das notações, pudemos constatar que: a) é sobretudo pelo desenho que as formas mais adiantadas de conceber a divisão são expressas; b) as notações por algarismos e por escrita alfabética representam, em sua maior parte, formas aditivas de conceber a divisão: repartir resulta em repetir partes iguais, uma das características mais marcantes dessa forma de conceber a divisão.

Diversamente, também, do ocorrido com as notações de igualização de parcelas, as notações relativas à repartição trazem, em geral, tanto o registro de estados, sobretudo o final (resultado) e, depois, o inicial (o total a repartir), como o da transformação efetuada nas coleções, a repartição registrada por traços de separação, como vimos. Segundo essa perspectiva, manifesta-se a tendência em registrar, antes, o estado final da transformação efetuada para, registrada essa transformação, marcar também o estado inicial (Vergnaud, 1985, 1990).

Assim sendo, as características das notações obtidas, os modos de sua produção e suas interpretações apontam ao menos três principais formas, hierarquicamente ordenáveis, de as crianças estudadas tratarem a divisão, a saber: ausência da noção de divisão, concepção aditiva da divisão e a concepção elementar de divisão.

A primeira dessas formas, da ausência da noção, revela a idéia de que partes não resultam da atividade de repartir. Predomina a idéia de que o total (dividendo) deve ser mantido, apesar de rememorada a distribuição ou repartição anterior de seus elementos em partes, seja esse total não equivalente ou equivalente ao trabalhado.

A segunda, da concepção aditiva da divisão, manifestase mediante as seguintes variações progressivas:

$1^{\text {a }}$ - presença da idéia de que somente duas partes equivalentes resultam da repartição do total, logo, somente metades podem ser obtidas, sendo ignorado o resto de qualquer extensão.

$2^{\mathrm{a}}$ - presença da idéia de que partes equivalentes necessariamente são obtidas do repartir. Mas estas partes são indistintas do total repartido, tendo então extensão e ele equivalente, logo, duplicando-o, posto que baseada na adição das partes.

$3^{2}$ - presença da idéia de partes equivalentes, resultantes da repartição do total, mas vistas como parcelas de uma adição cujo resultado é identificado com o total. Assim, a ação de repartir corresponde à decomposição do todo em partes iguais, mas seu resultado não é esta parte (quociente), mas sua recomposição aditiva. Ajustes pela retirada de um ou mais elementos em excesso nas partes são justificados, mas estes elementos não são redistribuídos. E o número de 
partes (divisor) pode ser ou não o da repartição antes trabalhada.

A terceira forma, a concepção elementar de divisão, manifesta-se pela:

$1^{a}$ - presença de idéia básica do repartir com ênfase no resultado da ação. Mediante provocação, ocorrem identificações pontuais: do dividendo, das partes obtidas como sendo "de todos e de cada um", do resto. Há ainda confusão entre divisor e quociente e entre dividendo e quociente, e o resto admitido é somente o de um elemento.

$2^{a}$ - presença da idéia elementar de divisão, com identificações dos termos da operação e das relações entre eles, com ênfase na descrição da ação de repartir.

\section{Discussão e Considerações Finais}

Em atenção ao primeiro objetivo deste estudo, a descrição das notações das crianças confirmou a presença esperada de desenhos, algarismos e escritas alfabéticas, como suas principais categorias. Presença esperada porque os principais tipos de marcas de que a cultura humana se serve para registrar sua quantificação da realidade (H. Sinclair, 1990) foram sugeridas pelo adulto durante as tarefas, ali aparecendo, inclusive, combinadas entre si.

Esse emprego combinado de marcas das diferentes categorias salienta a rica atividade infantil de representação, quando as crianças mostram-se capazes de lançar mão dos recursos de que dispõem para "dizer" o que assimilaram das tarefas. Em particular, o freqüente uso de desenho com algarismos, estes tantas vezes empregados como "etiqueta" do desenho para "deixar clara" a significação do desenhado, pode ser visto como indício de que, se têm algum conhecimento de tais formas de notação, podem as crianças ativamente passar de uma forma à outra. Isto lhes possibilita fazer as correspondências entre essas diferentes formas ao representar um mesmo significado, algo fundamental para a construção conceitual (Vergnaud, 1985).

Também, o emprego significativo pelas crianças de formas de marcar quantidades de que têm algum domínio destaca, mais uma vez, a proposição de que, para a progressão em direção a sistemas formais de escrita matemática, deve o professor apoiar-se nos quantificadores naturais de seus alunos. Essa transformação seria mais provável em situações de aprendizagem mais abertas, do gênero das utilizadas neste estudo, quando a intervenção docente, de caráter provocador, parte das elaborações típicas das crianças em progressão.

Contudo, não podemos esquecer que a alternância cíclica entre as tarefas de notação interpretada com as de execução prática interpretada relativas aos conceitos trabalhados foi um aspecto provavelmente muito fértil das situações empregadas. Como dissemos antes, essa alternância foi planejada com a intenção de ativar a tomada de consciência das ações e seus resultados na construção das relações focalizadas.

Porém, a análise do processo de produção de notações que fizemos não permite demonstrar o papel específico, supostamente necessário e fundamental, daquele processo de tomada de consciência conforme a perspectiva de Piaget (1974, 1978). Não analisamos a relação e as diferenças qualitativas entre as referidas realizações, em seus patamares de transformação, e as execuções práticas interpretadas que as antecediam ou sucediam. Esta é uma tarefa futura que os resultados do presente trabalho nos exige. Temos, tão somente, indícios fortes da ocorrência daquele processo ao assinalarmos o quanto, para muitas das crianças, parece ter sido a interpretação de suas notações e/ou a das notações dos parceiros o que desencadeou hesitações sobre o sentido de suas próprias marcas, com muitas alterações se lhes seguindo.

É segundo a idéia da provável relevância da tomada de consciência de suas produções para o processo de conceitualização, que os resultados do estudo sublinham, novamente, a necessidade de que, na escola, ocorra a compreensão dos sistemas de notação matemática como parte transformadora inerente à construção dos campos conceituais da área.

Outra dimensão de interesse de nossos resultados diz respeito à hierarquia entre desenhos e algarismos como tipos de notação, possibilidade que a literatura muitas vezes nos coloca (H. Sinclair, 1988; A. Sinclair, 1990). Porém, no conjunto das notações obtidas, há ausência daquela hierarquia entre notações de igualização, mas entre as de repartição aquela hierarquia se esboça. Ademais, escritas alfabéticas só são usadas para registrar as repartições.

A ausência da hierarquia entre notações matemáticas de desenho e algarismos pode ser atribuída à utilização mecanizada dos numerais, assim aprendidos pelas crianças, numerais então evocados ao acaso, sem qualquer significação quantitativa mais avançada (Gelman \& Meck, 1991). É o caso das notações de parcelas não igualizadas e igualizadas deste estudo: muitas delas retratam o uso mecanizado de numerais, assim como muitas notações em desenho são assim produzidas, representando tanto totais como parcelas. Em desenho ou em algarismos, as notações mais adiantadas guardam uma certa correspondência entre si ao retratarem, como antes descrito, a mesma tendência de construção das relações aditivas, ou seja, o movimento progressivo do registro de coleções totais não parceláveis para o de parcelas adicionáveis segundo as transformações aditivo-subtrativas ocorridas.

Portanto, mais do que os aspectos externos inerentes ao desenho ou aos algarismos em si próprios, o que contaria no seu emprego com sentido seria o plano de elaboração dos 
conceitos trabalhados em que as crianças se encontram. Isto nos leva à proposição de que, não só a apreensão dos conceitos e a representação semiótica seriam mesmo processos inseparáveis (Teixeira, 2001), mas também que, em situação pedagógica mais favorável àquela apreensão, as crianças podem ativamente reorganizar seus recursos de representação, inclusive dando novo sentido aos símbolos da matemática escolar aos quais já tenham sido expostas.

Porém, o que dizer sobre a hierarquia relativa entre desenhos, por um lado, e algarismos e escritas alfabéticas pelo outro, nas tarefas de repartição? E sobre o fato de escritas alfabéticas terem aparecido somente para marcar as repartições?

Muitos dos argumentos acima expostos mais a idéia da inseparabilidade entre a apreensão conceitual e a representação semiótica podem explicar também o fato de os desenhos serem notações de repartição pelas quais formas mais adiantadas de conceber a divisão são representadas, enquanto algarismos e escritas alfabéticas expressam formas menos adiantadas, em especial, a concepção aditiva de divisão. Para as crianças cuja apreensão conceitual da divisão é mais avançada, ainda que elementar, como descrito, não poderia ser diferente: o desenho, uma forma de representação icônica, está, em geral, disponível em seu repertório, antes da escrita de algarismos e da escrita alfabética. Assim, o desenho vemlhes a ser um recurso praticamente "natural" para marcar: $\mathrm{O}$ total repartido, o resultado dessa repartição e a ação mesma de repartir (a transformação).

Embora já dominando a divisão naquele plano mais avançado, crianças, como as estudadas, desconhecem ainda os sinais aritméticos para a divisão, as formas canônicas de expressar as relações de divisão. Porém, já podem formular algumas dessas relações a seu modo; por exemplo, na falta de outro recurso, podem dispor da escrita alfabética para descrever o repartir efetuado, ainda que esse tipo de notação tenha seus limites, do que adviria sua baixa freqüência no estudo.

Já para as crianças cuja compreensão da divisão é ainda aditiva ou para quem o repartir uma grandeza ainda não resulta em uma parte específica, o quociente, algarismos (e eventualmente escrita alfabética) estariam disponíveis para registrar os termos da adição ali vista e seu resultado ou, somente, a coleção total.

Das notações em escrita alfabética, embora muito menos freqüentes, temos a riqueza de elaboração que elas podem expressar e provocar. Logo, na escola, as crianças devem ser levadas a descrever estados e transformações, para construir estruturas aritméticas e para compreender o sistema notacional da matemática a elas pertinente.

Portanto, sobre a relativa hierarquia dos tipos de notação descritos, vimos que os desenhos, como representação icônica, servem, mas não obrigatoriamente, à explicitação de formas mais avançadas de conceber as relações aritméticas focalizadas, antes de algarismos e escritas alfabéticas porque estes tipos de notação estariam transformando-se paralelamente, posto que dependentes de domínio de habilidades específicas relativas à escrita alfabética e à escrita matemática.

No entanto, o nível de apreensão conceitual específico em que estão as crianças é crucial na forma de representar significativamente essa compreensão. Logo, de novo, se margem é dada, na escola, para as crianças ativamente trabalharem conceitos e relações e, também, produzirem uma notação que lhes tenha sentido como representação do que estão compreendendo, elas lançam mão dos vários tipos de marcas que conhecem como meio de "dizer" o que estão compreendendo.

Uma outra diferença entre as notações descritas para a igualização e para a repartição está na presença predominante de marcas para os estados, inicial e final, nas primeiras (parcelas e seu total), enquanto que nas segundas preponderam as marcas para o estado final (resultado do repartir), freqüentemente seguidas de marcas para a transformação efetuada (o repartir). Logo, marcas para as transformações aditivas e subtrativas de parcelas iguais e desiguais são muito pouco encontradas. Como explicar essa diferença?

Nas tarefas de igualização, executadas antes das de repartição, as crianças produziam suas notações podendo observar as parcelas antes compostas com o material (parcelas equivalentes ou não). Passavam então, muitas delas, a desenhar o total (conferindo por contagem os elementos desenhados e/ou os das parcelas compostas), disso tudo resultando marcas para os estados inicial e final, mas não para a ações aditivas ou subtrativas de transformação. Estas, mesmo sendo evocadas às questões provocadoras do adulto, não eram vistas como algo a ser necessariamente marcado, mesmo porque o desenho da coleção total já registrava o resultado da ação aditiva, ao menos.

Entretanto, nessas mesmas circunstâncias, de algumas crianças houve, nos desenhos, marcas relativas à transformação (o acrescentar e o retirar elementos), ou registro da adição no formato canônico com o sinal aritmético convencional devidamente visto como marca dessa relação.

Julgamos que a razão central dessas manifestações estaria nos níveis de compreensão das estruturas aditivas das crianças examinadas e cujo movimento progressivo já descrevemos: da pregnância ainda forte da apreensão de estados, realidades quantificadas estáticas, para a apreensão das relações de transformação reversível dessas realidades, tendo como correspondentes progressos das notações de coleções totais, não parceláveis, para as de parcelas adicionáveis segundo transformações aditivo-subtrativas. 
Desse modo, o expressivo predomínio de notações de estados (inicial e final) em relação a marcas para as transformações nos dizem que muitas das nossas crianças encontravam-se em um patamar ainda elementar de compreensão da composição de duas grandezas em uma terceira, uma das relações aditivas básicas (Vergnaud, 1985, 1989-1990, 1991). Teriam elas uma apreensão ainda muito figurativa dos estados inicial e final, este um total obtido pela iteração de ações de acrescentar $(+1,+1 \ldots)$ também preponderantes em relação ao retirar iterativo $(-1,-1 \ldots)$. A propósito, essa apreensão predominantemente figurativa é que daria sentido à idéia inicial de que somente parcelas iguais, simétricas, é que seriam adicionáveis.

Assim, o adicionar transformador das parcelas em outra grandeza não teria sido entendido por muitas das crianças e, muito menos, o teria o seu inverso, o subtrair. Não haveria ainda dessas crianças a tomada de consciência da relação de transformação aditiva de uma grandeza inicial em uma final e, então, da ação inversa de decomposição para obter parcelas quaisquer, cuja adição corresponde a esse mesmo total, mesmo porque também não estariam elas atribuindo valores cardinais estáveis a tais quantidades (exceto às de extensão numérica muito limitada). É importante lembrar que essa atribuição é tida como fruto de uma construção complexa das estruturas aditivas em seus níveis diversos (Vergnaud, 1981, 1991).

Em conseqüência, limitaram-se nossas crianças, em maioria, à idéia da subtração como perda de elementos. Estes tanto ficam "perdidos" que nem foram lembrados como tendo sido acrescentados à outra parcela para a igualização; ou nem foram lembrados como acrescentados, ficando excluídos na obtenção daquela igualização, conforme uma das tendências de construção que descrevemos. As comparações entre grandezas caracterizaram-se assim pela atribuição de grandezas absolutas na avaliação de cada parcela, ausentes as avaliações relativas ligadas a concepções mais avançadas de subtração (o resultado como quantidade complementar ou como diferença relativa entre estados sucessivos, por exemplo), em acordo com outra das tendências de construção descritas para as relações aditivas (Vergnaud, 1985, 1989-1990). Mas, nessa perspectiva, por que a presença maior de marcas para a transformação das coleções totais feitas após as do estado final (resultado) nas tarefas de repartição?

Nessas tarefas, as crianças também fizeram notações observando as coleções de elementos resultantes do repartir uma coleção, antes efetuado com o material. Nada de surpreendente então que, primeiro, muitas delas desenhassem essas partes para, adiante, traçarem marcas de separação entre as partes, assim identificando-as melhor em extensão e número; ou desenhassem a separação em partes no próprio desenho da coleção total, assim registrando o estado inicial (dividendo) seguido da ação que o transformava em partes.

Por outro lado, da literatura referida temos a precocidade das crianças em repartir coleções por distribuição um a um, principalmente, quando da repartição em duas partes. Logo, o repartir seria também mais facilmente marcado do que as transformações aditivo-subtrativas de elementos, um a um (as que resultam, sobretudo, em parcelas diferentes) porque partes iguais, simétricas, seriam mais pregnantes à apreensão inicial figurativa das crianças do que partes desiguais que decompõem um total. Esse aspecto, aliado a outras significações de ordem afetivo-social sobre as partes resultantes do repartir terem que ser iguais (algo muito presente nas falas das crianças) pode falar a favor da presença tão marcante do repartir nas produções infantis (Moro, 1999).

Entretanto, nenhuma marca para transformações pelo repartir foi feita por crianças que não dispunham de qualquer noção de divisão. Mesmo provocadas a evocar o repartir recém executado, essas crianças limitavam-se principalmente a desenhar a coleção total, muitas vezes a partir da contagem de todos os elementos arranjados nas partes antes obtidas.

Vemos assim que, afora as peculiaridades da presença do repartir no repertório de crianças como as examinadas, também nesse caso há que se levar em conta os patamares de compreensão da divisão identificados, os quais parecem estar estreitamente ligados àquela presença: se, na ausência de qualquer idéia de divisão, de fato não há como registrar significativamente aquela transformação, aos outros patamares de compreensão correspondem expectativas de marcas para o repartir como ação que produz a) partes mas que são adicionáveis, como no caso da concepção aditiva de divisão, desenhadas ou com algarismos, ou b) partes equivalentes que estão contidas certo número de vezes na coleção total ou a elas correspondem, como também partes conforme cada termo de uma divisão.

As tendências específicas de construção das relações aditivo-subtrativas que puderam ser identificadas das notações interpretadas apontam, como discutimos, a relevância e a complexidade da construção dos esquemas de igualar e desigualar na síntese das transformações aditivosubtrativas. E, por seu lado, os diversos planos de compreensão da divisão descritos a partir das notações de repartição destacaram o lugar do repartir grandezas nesse processo.

Porém, que sinais de relações psicogenéticas entre estruturas aditivas e multiplicativas as transformações desses esquemas estariam revelando? Como pensávamos, compor e decompor uma totalidade em partes equivalentes e/ou não equivalentes, como provocado nas tarefas de igualização de parcelas e de repartição, pode ser visto como esquema invariante inerente àquelas relações? 
A análise das notações descritas muito parece dizer sobre a relevância da composição e da decomposição de grandezas, uma expressão da relação parte-todo, na identificação das raízes das estruturas multiplicativas nas aditivas porque: a) no caso da adição-subtração, tais esquemas produzem parcelas de grandezas diversas; assim, combinando-se em um sistema de transformações, permitem apreender tais parcelas como transformáveis a cada e a qualquer momento sem alteração de seu total; b) no caso da divisão, a faceta ora abordada das estruturas multiplicativas, aqueles esquemas (compordecompor grandezas), como transformadores, encaminhariam a obtenção e a identificação de partes de extensão equivalente e em certo número (como componentes do todo), colocando em cena os termos da divisão e as relações entre eles.

Nessa ótica, as ações de igualar e desigualar em ligação estreita com as de repartir quantidades numéricas seriam centrais para, interdependentes, ativar a coordenação entre estados, logo, a conceitualização de ações de transformação, uma das possíveis formas de ver a inter-relação das estruturas aditivas com as multiplicativas.

Porém, nossos resultados também indicam que o lugar atribuído ao compor e ao decompor partes na psicogênese das estruturas multiplicativas nas aditivas focalizadas não exclui outros invariantes de relevância. O que encontramos aponta, mais uma vez, para o que é tido como uma construção árdua e lenta de relações aritméticas, um processo que apoiase em diversos invariantes em elaboração, entre os quais a correspondência operatória, logo reversível, entre quantidades. Vemos esta, em conjunto com a relação inclusiva parte-todo da composição-decomposição aditivo-subtrativa, como de presença necessária na compreensão da cardinalidade das coleções numéricas.

As notações que obtivemos muito sugerem sobre o significado da compreensão do valor cardinal das coleções no domínio e avanço das relações aritméticas para outros planos. Mas também a idéia da cardinalidade é construída em trama conjunta progressiva com os demais invariantes o que, no caso das relações da divisão (entre dividendo, divisor e quociente), pode encontrar seu exemplo na identificação de uma grandeza que se conserva, e que é decomposta (e/ ou recomposta) em um número de partes, para resultar em partes equivalentes, sendo o número dessas partes inferido como o número de "partições" operando sobre a totalidade (Moro, 1999).

Portanto, independentemente das particularidades das ações de igualar-desigualar e de repartir de nossas tarefas, os avanços de compreensão tanto das relações aditivosubtrativas como os das relações envolvidas na divisão, tal como revelados nas notações produzidas, têm na compreensão do valor cardinal de coleções uma dimensão essencial para que as crianças possam estabelecer relações aditivo-subtrativas reversíveis, logo, estáveis entre parcelas, e identificar o número de partes equivalentes de uma totalidade e a extensão dessas partes como quociente.

Ao argumentar a favor do lugar relevante de alguns esquemas na passagem das estruturas aditivas e multiplicativas elementares, como fizemos neste estudo, não estamos excluindo a probabilidade de muitos outros esquemas, tão ou mais centrais, estarem no âmago de tais inter-relações psicogenéticas. Por conseguinte, outros estudos tornam-se necessários para melhor esclarecer tais relações na complexa construção da aritmética infantil.

Para finalizar, destacamos que se a análise das notações das crianças permitiu-nos chegar a invariantes que estariam nas raízes de estruturas multiplicativas nas aditivas, parece claro que a construção desses invariantes não só é revelada, como se faz no processo mesmo da elaboração das notações. Então, novamente destacamos o quanto, na escola, a produção de notações significativas às crianças é medida pedagógica de relevo na elaboração dos sistemas da escrita numérica, como parte inerente da aprendizagem da matemática.

\section{Referências}

Baroody, A. J. \& Ginsburg, H. F. (1986). The relationship between initial meaningful and mechanical knowledge of arithmetic. Em J. Hiebert (Org.), Conceptual and procedural knowledge: The case of mathematics (pp. 75-112). London/Hillsdale: Lawrence Erlbaum.

Bideaud, J., Meljac, C. \& Fischer, J. P. (Orgs.) (1991). Les chémins du nombre. Lille, Presses Universitaires de Lille.

Brun, J., Giossi, J. M. \& Henriquès, A. (1984). À propos de l'écriture décimale. Math-École, 23(112), 2-11.

Carraher, T., Carraher, D. \& Schliemann, A. D. (1989). Na vida dez, na escola zero ( $3^{\mathrm{a}}$ ed.). São Paulo: Cortez.

Correa, J. (1996). A compreensão inicial do conceito de divisão partitiva em tarefas não-computacionais. Em M. H. Novaes \& M. R. F. de Brito (Orgs.), Psicologia na educação: Articulacãa entre pesquisa, formação e prática pedagógica (Coletâneas da ANPEPP, vol 1, no 5, pp. 151-165). Rio de Janeiro: Associação Nacional de Pesquisa e Pós-Graduação em Psicologia/Xenon.

Correa, J., Nunes, T. \& Bryant, P. (1998). Young children's understanding of division: The relationship between division terms in a non-computational task. Journal of Educational Psychology, 90(2), 321-329.

Doise, W. \& Mugny, G. (1981). Le développement social de lintelligence. Paris: InterÉditions.

Gardin, J. C. (1974). Les analyses de discours. Neuchâtel: Delachaux et Niestlé.

Gelman, R. \& Meck, E. (1991). Premiers principes et conceptions du nombre. Em J. Bideaud, C. Meljac \& J. P. Fischer (Orgs.), Les chémins du nombre (pp. 211-234). Lille: Presses Universitaires de Lille.

Gillièron, C. (1980). El psicopedagogo como observador: Por qué y como. Infancia e Aprendizaje, 9, 7-21

Gréco, P., Grize, J.-B., Papert, S. \& Piaget, J. (1960). Problèmes de la construction du nombre. Études d'Epistémologie Génétique (Vol. XI). Paris: PUF.

Gréco, P. \& Morf, A. (1962). Les structures numériques elémentaires. Études d'Epistémologie Génétique (Vol. XIII.). Paris: PUF.

Higino, Z. (1997). Desenvolvendo a compreensão da notação escrita do sistema de numeração. Em UFPE/Mestrado em Psicologia (Org.), Anais da II Semana de Estudos em Psicologia da Educação Matemática (pp. 46-53). Recife: Universidade Federal de Pernambuco. 
Janvier, C. (Org.) (1987). Problems of representation in the teaching and learning of mathematics. London/Hillsdale: Lawrence Erlbaum.

Kamii, C. \& DeClark, G. (1985). Young cbildren reinvent mathematics. New York/ London: Teachers College Press.

Kornilaki, E. \& Nunes, T. (1999). Do multiplication and division develop in parallel or as co-ordinated operations? Em European Society of Developmental Psychology (Org.), IXth. European Conference on Developmental Psychology: Human Development at the Turn of the Century. Abstracts (pp. 389-390). Spetses: ESDP/ University of Athens.

Lerner de Zunino, D. (1995). A matemática da escola: Aqui e agora. (J. A. Llorens, Trad.) ( $2^{a}$ ed.). Porto Alegre: Artes Médicas. (Original s/d)

Lerner, D. \& Sadovsky, P. (1996). O sistema de numeração: Um problema didático. Em C. Parra \& I. Saiz (Orgs.), Didática da matemática. Reflexões psicopedagógicas (J. A. Llorens, Trad.) (pp. 73-155). Porto Alegre: Artes Médicas. (Original publicado em 1994)

Moro, M. L. F. (1999). Aprendizagem construtivista de estruturas aditivas e multiplicativas na iniciação matemática. Temas em Psicologia da SBP, 7(3), 263282.

Nunes, T. \& Bryant, P. (1997). Crianças fazendo matemática (S. Costa, Trad.). Porto Alegre: Artes Médicas.

Orozco-Hormaza, M. (2002, junho). Los errorres sintácticos cuando los niños aprenden a escribir numerales. Trabalho apresentado em simpósio no $32^{\text {nd }}$, Annual Meeting of the Jean Piaget Society. Philadelphia, USA. (material não-publicado)

Parrat-Dayan, S. (1980). Étude génétique de l'acquisition de la notion de moitié. Genève: Edition J. R. de Rougemont.

Parrat-Dayan, S. (1985). À propos de la notion de moitié: Rôle du contexte expérimental. Archives de Psychologie, 53, 433-438.

Perret, J.-F. (1985). Comprendre l'écriture des nombres. Berne Peter Lang.

Piaget, J. (1974). La prise de conscience. Paris: PUF.

Piaget, J. (1978). Fazere compreender. (C. L. de P. Leite, Trad.). São Paulo: EDUSP/ Melhoramentos. (Original publicado em1974)

Piaget, J. \& Szeminska, A. (1971). A gênese do número na criança (C. M. Oiticica, Trad.). Rio de Janeiro: Zahar. (Tradução da $3^{a}$ edição de 1964)

Piaget, J. (Org.) (1977). Recherches sur l'abstraction réfléchissante. 1/ L'abstraction des relations logico-arithmétiques. Études d'Epistémologie Génétique (Vol. XXXIV). Paris: PUF.

Piaget, J. (1996). As formas elementares da dialética (F. M. Luiz, Trad.). São Paulo: Casa do Psicólogo. (Original de 1980)

Schubauer-Leoni, M-L. \& Perret-Clermont, A-N. (1980). Interactions sociales et répresentations symboliques dans le cadre de problèmes additifs. Recherches en Didactique des Mathématiques, 1, 2, 3, 297-350.

Schubauer-Leoni, M.-L. \& Perret-Clermont, A. -N. (1984). Construction sociale d'écritures symboliques en deuxième primaire (opérations addtitives). Interactions Didactiques, 4, 1-40.

Selva, A. C. V. \& Brandão, A. C. P. (2000). A notação escrita na resolução de problemas por crianças pré-escolares. Psicologia: Teoria e Pesquisa,16(3) 241-249.

Seron, X., Deloche, G. \& Noël, M.-P. (1991). Un transcodage des nombres chez l'enfant: la production des chiffres sous dictée. Em J. Bideaud, C. Meljac \& J. P. Fischer (Orgs.), Les chémins du nombre (pp. 303-327). Lille: Presses Universitaires de Lille.

Sinclair, A. (1990). A notação numérica na criança. Em H. Sinclair (Org.), A produção de notaçoes na criança (M. L. F. Moro, Trad.) (pp. 71-96). São Paulo: Cortez. (Original publicado em 1988)

Sinclair, A. \& Scheuer, N. (1993). Understanding the written system: 6 year-olds in Argentina and Switzerland. Educational Studies in Mathematics, 1-23 (separata).
Sinclair, A., Tièche-Christinat, C. \& Garin, A. (1994). Comment l'enfant interprètet-il les nombres écrits à plusieurs chiffres? Em M. Artigue, R. Gras, C. Laborde \& P. Tavignot (Orgs.), Vingt ans de didactique des mathématiques en France (pp. 243-249). Grenoble: La Pensée Sauvage.

Sinclair, H. (1988). Learning: The interactive re-creation of knowledge. Trabalho comunicado no VI International Congress of Mathematics Education. Budapest: ICME (mimeo).

Sinclair, H. (1990). Introdução. Em H. Sinclair (Org.), A produção de notaçẽes na crianca (M. L. F. Moro, Trad.) (pp. 13-18). São Paulo: Cortez. (Original publicado em 1988)

Sinclair, H. \& Sinclair, A. (1986). Children's mastery of written numerals and the construction of basic number concepts. Em J. Hiebert (Org.), Conceptual and procedural knowledge: The case of mathematics (pp. 59-74). London/Hillsdale: Lawrence Erlbaum.

Squire, S. \& Bryant, P. (2002). From sharing to dividing. Young children's understanding of division. Trabalho apresentado em simpósio no $32^{\text {nd }}$ Annual Meeting of the Jean Piaget Society. Philadelphia, USA. (material não-publicado)

Squire, S., Bryant, P. \& Correa, J. (1999). Young children's understanding of division. Em European Society of Developmental Psychology (Org.), IXth European Conference on Developmental Psychology: Human Development at the Turn of the Century. Abstracts (p. 389). Spetses: University of Athens/European Society for Developmental Psychology.

Teixeira, L. R. M. (1996). Aprendizagem inicial do valor posicional dos números: conceituação e simbolização. Trabalho apresentado na Homenagem LatinoAmericana pelo Centenário de Nascimento de Jean Piaget. São Paulo: Universidade de São Paulo. (trabalho não-publicado)

Teixeira, L. R. M. (2001). As notações numéricas como representação semiótica: O ensino e a aprendizagem do sistema de numeração posicional. Anais da XXXI Reunião Anual de Psicologia da Sociedade Brasileira de Psicologia (p. 68). Rio de Janeiro: SBP/UERJ.

Vergnaud, G. (1981). Quelques orientations théoriques et méthodologiques des recherches françaises en didactique des mathématiques. Recherches en Didactique des Mathématiques, 2(2), 215-232.

Vergnaud, G. (1985). L'enfant, la mathématique et la réalité (3a ed.). Berne: Peter Lang.

Vergnaud, G. (1989-1990). Psichologie du développement et didactique des mathématiques. Un exemple: Les structures additives. Petit x, 22, 51-69.

Vergnaud, G. (1990). La théorie des champs conceptuels. Recherches en Didactiques des Mathématiques, 10(23), 133-170.

Vergnaud, G. (1991). L'appropriation du concept de nombre: un processus de longue haleine. Em J. Bideaud, C. Meljac \& J.- P. Fischar (Orgs.), Les chemins du nombre (pp. 271-282). Lille: Presses Universitaires de Lille.

Vergnaud, G. (1994). Le rôle de l'enseignant à la lumière des concepts de schème et de champ conceptuel. Em M. Artigue, R. Gras, C. Laborde \& P. Tavignot (Orgs.), Vingt ans de didactique des mathématiques en France (pp. 177-191). Grenoble: La Pensée Sauvage.

Vergnaud, G. (1996). Au fond de l'action, la conceptualisation. Em J. M. Barbier (Org.), Savoirs théoriques et savoirs d'action (pp. 275-292). Paris: PUF.

Vergnaud, G. (1998). Algebra, additive and multiplicative structures. Is there any coherence at the early secondary level? Paris: CNRS/Université de Paris 8. (material nãopublicado)

\section{Sobre a autora}

Maria Lucia Faria Moro é Doutora em Psicologia da Educação pela Pontifícia Universidade Católica de São Paulo, Professora Titular de Psicologia da Educação pela Universidade Federal do Paraná. Atualmente é professor pesquisador sênior do Programa de Pós-Graduação em Educação/ Mestrado e Doutorado da Universidade Federal do Paraná. 